ARTICLE

https://doi.org/10.1038/s41467-019-11239-0

\title{
Antimalarial activity of primaquine operates via a two-step biochemical relay
}

\author{
Grazia Camarda1, Piyaporn Jirawatcharadech', Richard S. Priestley (1) 1,7, Ahmed Saif 1,8, Sandra March², \\ Michael H.L. Wong (1D ${ }^{3}$, Suet Leung ${ }^{3}$, Alex B. Miller ${ }^{2}$, David A. Baker (D) ${ }^{4}$, Pietro Alano ${ }^{5}$, Mark J.I. Paine (D) ${ }^{6}$, \\ Sangeeta N. Bhatia ${ }^{2}$, Paul M. O'Neill ${ }^{3}$, Stephen A. Ward ${ }^{1} \&$ Giancarlo A. Biagini (i) ${ }^{1}$
}

Primaquine (PQ) is an essential antimalarial drug but despite being developed over 70 years ago, its mode of action is unclear. Here, we demonstrate that hydroxylated-PQ metabolites $(\mathrm{OH}-\mathrm{PQm})$ are responsible for efficacy against liver and sexual transmission stages of Plasmodium falciparum. The antimalarial activity of $\mathrm{PQ}$ against liver stages depends on host CYP2D6 status, whilst OH-PQm display direct, CYP2D6-independent, activity. PQ requires hepatic metabolism to exert activity against gametocyte stages. $\mathrm{OH}-\mathrm{PQm}$ exert modest antimalarial efficacy against parasite gametocytes; however, potency is enhanced ca.1000 fold in the presence of cytochrome P450 NADPH:oxidoreductase (CPR) from the liver and bone marrow. Enhancement of $\mathrm{OH}-\mathrm{PQm}$ efficacy is due to the direct reduction of quinoneimine metabolites by CPR with the concomitant and excessive generation of $\mathrm{H}_{2} \mathrm{O}_{2}$, leading to parasite killing. This detailed understanding of the mechanism paves the way to rationally re-designed 8-aminoquinolines with improved pharmacological profiles.

\footnotetext{
${ }^{1}$ Centre for Drugs and Diagnostics Research, Tropical Disease Biology Department, Liverpool School of Tropical Medicine, Liverpool L3 5QA, UK. ${ }^{2}$ Health Sciences and Technology/Institute for Medical Engineering and Science, Massachusetts Institute of Technology, Cambridge, MA 02139, USA. ${ }^{3}$ Department of Chemistry, University of Liverpool, Liverpool L69 7ZD, UK. ${ }^{4}$ Faculty of Infectious and Tropical Diseases, London School of Hygiene \& Tropical Medicine, London WC1E 7HT, UK. ${ }^{5}$ Dipartimento di Malattie Infettive, Istituto Superiore di Sanità, Rome 00161, Italy. ${ }^{6}$ Vector Biology Department, Liverpool School of Tropical Medicine, Liverpool L3 5QA, UK. ${ }^{7}$ Present address: ARUK Oxford Drug Discovery Institute, University of Oxford, Oxford OX3 7FZ, UK. ${ }^{8}$ Present address: Clinical Laboratory sciences Department, College of Applied Medical Sciences, Najran University, Najran 61441, Saudi Arabia. Correspondence and requests for materials should be addressed to G.A.B. (email: Giancarlo.Biagini@lstmed.ac.uk)
} 
S ince its development in the 1950s by the US Army, an estimated 200 million people have been administered $\mathrm{PQ}^{1}$. Research into the elusive PQ mode of action has mainly focused on the identification of the biochemical basis for its side effect of hemolytic toxicity in patients with G6PD deficiency ${ }^{1}$. Earlier studies led to the identification of $\mathrm{OH}-\mathrm{PQm}$, generated from hepatic phase I metabolism ${ }^{2}$, as potential culprits for toxicity 3,4 . The most relevant species in this context include the 5-hydroxy (5-HPQ) and 5,6-dihydroxy (5,6-DPQ) primaquine metabolites (Fig. 1a). These species are unstable, undergoing spontaneous oxidation and producing the corresponding quinoneimine forms (Fig. 1a, PQQI, 5-quinoneimine, and 6OHPQQI, 6-hydroxy-5-quinoneimine) with concomitant generation of $\mathrm{H}_{2} \mathrm{O}_{2}{ }^{5}$; quinoneimine metabolites can then be reduced back to the hydroxylated form, leading to $\mathrm{H}_{2} \mathrm{O}_{2}$ accumulation. However, their reduction potential is likely to be very negative, limiting the pool of possible intracellular reductants with a sufficiently low reduction potential to donate electrons. In proof-of-concept studies using the strong reducing enzyme, ferredoxin-NADP reductase (FNR) from spinach (note the $E_{\mathrm{m}, 7}$ known for the ferredoxin oxidised/reduced couple is ca. $-430 \mathrm{mV}$ ), PQ quinoneimines were shown to be enzymatically reduced ${ }^{5}$-but despite intensive research efforts the exact enzyme(s) and metabolic pathway(s) involved in the process remain to be fully elucidated.

Similarly, the mechanism of action of primaquine against the malaria parasite is also largely unknown ${ }^{6,7}$. A link between drug efficacy and metabolism through CYP2D6 is supported by recent animal and clinical studies, including the association of CYP2D6 poor metaboliser phenotype status with primaquine failure in controlled human malaria infections with $P$. vivax ${ }^{2,8}$. The need for CYP2D6 metabolism to generate key $\mathrm{OH}-\mathrm{PQm}^{9,10}$ supports the assumption that these metabolites contribute to drug efficacy; however, hitherto there has been no direct demonstration of the link between these metabolites and anti-parasitic activity. Any explanation of PQ action needs to address the exquisite selectivity against dormant and active liver stage parasites and the ability of very low drug doses and subsequent low systemic exposures to kill gametocyte stages of $P$. falciparum clinically ${ }^{11}$. This study attempts to reconcile these questions.

Here $\mathrm{OH}-\mathrm{PQm}$ in their hydroxyquinoline or quinoneimine form have been synthesised and assessed for their activity against $P$. falciparum gametocytes and liver stages. By assessing parasite viability in the presence or absence of metabolic conversion we a<smiles>COc1cc(NC(C)CCCN)c2ncccc2c1</smiles>

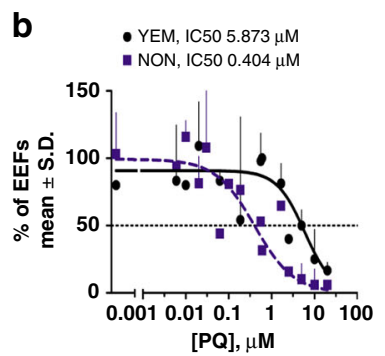

g

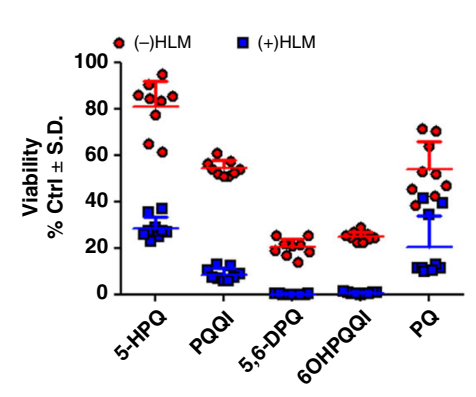

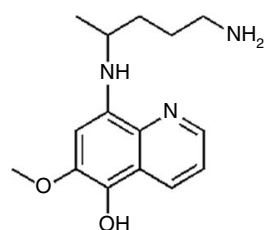
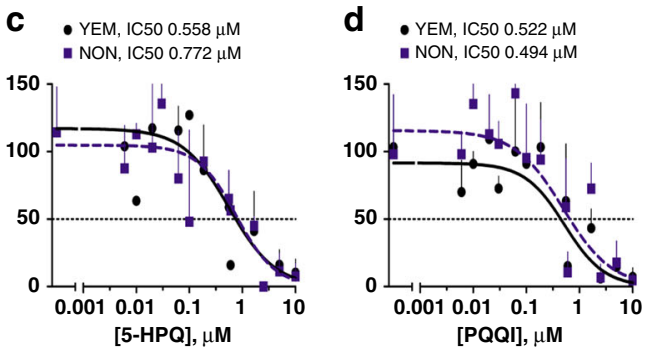
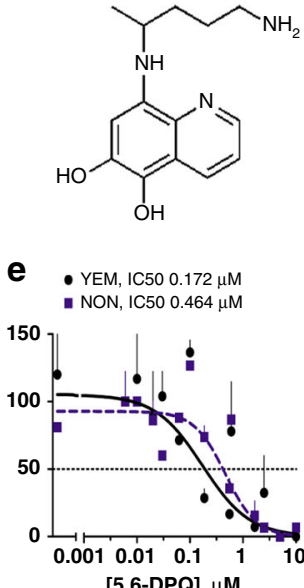

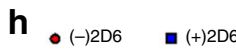

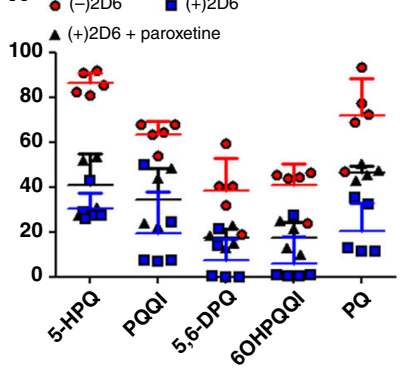

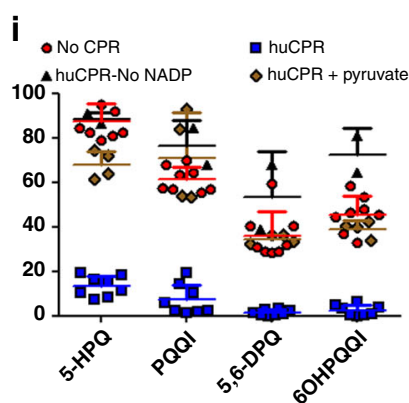<smiles>CC(CCCN)/N=C1\C=C(O)C(=O)c2cccnc21</smiles>

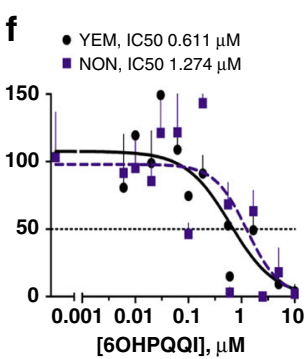

Fig. 1 Structures of $\mathrm{PQ}$ and $\mathrm{OH}-\mathrm{PQm}$ and their activity against $P$. falciparum liver stages and gametocytes. a Structures of compounds used in this study. b, $\mathbf{f}$ Dose dependent reduction in exoerythrocytic forms (EEFs) numbers at day 3.5 post infection with NF54 sporozoites in YEM (poor metaboliser, black line) and NON (extensive metaboliser, dashed blue line) hepatocyte lots. b Primaquine (PQ). c 5-hydroxy-primaquine (5-HPQ). d 5-quinoneimine (PQQI). e 5,6-dihydroxy-primaquine (5,6-DPQ). $\mathbf{f}$ 6-hydroxy-5-quinoneimine (6OHPQQI). Viability is expressed as mean percentage of vehicle control \pm S.D. of two independent experiments performed in triplicates. For each drug, IC 50 values are reported for the poor metaboliser, YEM, and extensive metaboliser, NON, hepatocyte lots. $\mathbf{g}$ Coupled in vitro metabolism-GC-LUC assay. PQ and PQ metabolites $(30 \mu \mathrm{M})$ were reacted with (blue squares) or without (red circles human liver microsomes (HLM) prior to dilution to $10 \mu \mathrm{M}$ (nominal parental compound concentration) in a GC-LUC assay with mature gametocytes. Viability was measured after $72 \mathrm{~h}$ and expressed as mean percentage of control (no drug) viability \pm S.D. ( $n=3$, each in triplicate). $\mathbf{h}$ as in g, but with (blue squares) or without (red circles) CYP2D6 ( $n=2,5$ total replicates). For paroxetine inhibition, CYP2D6 was pre-incubated with $10 \mu \mathrm{M}$ paroxetine for 15 min prior to compounds (black triangles, $n=2,4$ total replicates); $\mathbf{i}$ as in $\mathbf{g}$, but without (red circles) or with (blue squares) recombinant human CPR, or with huCPR in the presence of $10 \mathrm{mM}$ sodium pyruvate (brown diamonds) with huCPR in the absence of NAPD+ (black triangles). NoNADP $+n=1$ in duplicate; all other huCPR conditions $n=4$ in duplicate 
show that $\mathrm{OH}-\mathrm{PQm}$ full cidal potential requires further enzymatic catalysis. We identify the CYP2D6 redox partner, cytochrome P450 NADPH:oxidoreductase (CPR), as required for $\mathrm{OH}-\mathrm{PQm}$ to exert full gametocytocidal activity, independently of CYP2D6 status. We also show that $\mathrm{OH}-\mathrm{PQm}$ activity against $P$. falciparum liver stage development is comparable or better than PQ and confirm a dispensable role for CYP2D6 activity. Finally, we substantiate the critical role of $\mathrm{H}_{2} \mathrm{O}_{2}$ production in anti-parasitic activity and propose a CPR-mediated biochemical model to account for PQ and OH-PQm mechanism of action. These data answer long-held questions of why PQ displays parasite stage-specific activity and why PQ displays transmission blocking activity at such low doses.

\section{Results}

Influence of CYP2D6 on PQ antimalarial liver-stage activity. To explore the activity of $\mathrm{PQ}$ and $\mathrm{OH}-\mathrm{PQm}$ against $P$. falciparum liver stage development, we used an advanced in vitro model that consistently mimics liver physiology and supports complete maturation of $P$. falciparum extra-erythrocyte forms (EEFs) in the liver ${ }^{12}$. In this in vitro system, human primary hepatocytes are organised into colonies surrounded by supportive stromal cells (Micropatterned coculture, MPCC) and infected with $P$. falciparum (NF54 strain) sporozoites ${ }^{12}$. To evaluate the role of CYP2D6 in PQ and OH-PQm activity, we selected two hepatocyte lots, NON and YEM. YEM is a low metaboliser based on genotype analysis, it has a variation in the CYP2D6 allele $\left({ }^{*} 4{ }^{*} 4\right)$; this was confirmed by incubation with the CYP2D6 probe debrisoquine ${ }^{13}$ and measuring the metabolite 4-hydroxidebrisoquine by mass spectrometry (MS) (Supplementary Fig. 1), confirming that the NON hepatocyte lot had twofold higher CYP2D6 activity than the YEM lot.

$\mathrm{OH}-\mathrm{PQm}$ were synthesised and used alongside PQ to directly assess the inhibition of EEFs development in dose-response experiments in the two hepatocyte lots. As shown in Fig. 1b, PQ activity against EEFs development strictly depended on hepatocyte CYP2D6 status, with $>14$-fold increase in the $\mathrm{IC}_{50}$ measured in the YEM background (low metaboliser, PQ $\mathrm{IC}_{50} 5.87 \mu \mathrm{M}$ ) as compared to NON hepatocytes (extensive metaboliser PQ $\mathrm{IC}_{50}$ $0.40 \mu \mathrm{M})$. Conversely, all $\mathrm{OH}-\mathrm{PQm}$ showed comparable $\mathrm{IC}_{50}$ values in the two hepatocyte lots (Fig. 1c-f), indicating that they act independently of CYP2D6 activity. It is interesting to note that all $\mathrm{OH}-\mathrm{PQm}$ show similar potency against liver stages, comparable to that seen for PQ in the presence of extensive metaboliser hepatocytes. Taken together these results confirm that $\mathrm{OH}-\mathrm{PQm}$ have direct killing activity against liver stages, supporting the hypothesis that they act downstream of CY2D6 activity.

PQ gametocytocidal activity requires hepatic metabolism. We next explored the anti-gametocyte activity of OH-PQm and parental PQ through coupled in vitro metabolismgametocytocidal assays. In these assays, we first incubated PQ and $\mathrm{OH}-\mathrm{PQm}$ with human liver microsomes (HLM) to mimic bioactivation and then tested for gametocytocidal activity against a $P$. falciparum 3D7A transgenic strain, expressing luciferase specifically in the gametocyte stages ${ }^{14}$, in an improved gametocyte viability assay GC-LUC (gametocyte luciferase) ${ }^{14}$. As shown in Fig. 1g, PQ at $10 \mu \mathrm{M}$, as expected, has minimal activity in the absence of any metabolic conversion (red histograms, (-)HLM). When gametocytes were treated with $\mathrm{OH}-\mathrm{PQm}$, we observed little to moderate gametocytocidal activity, with only demethoxylated species, 5,6-DPQ and 6OHPQQI, able to reduce gametocyte viability to less than $50 \%$ of solvent control (Fig. 1g, (-)HLM). After HLM metabolism (Fig. 1g, blue histograms, (+)HLM), PQ gametocytocidal activity significantly increased, confirming that metabolic transformation is also required for gametocyte killing activity. Interestingly, a significant increase in potency was also observed for all OH-PQm after microsomal incubation ( $p$ value $<$ 0.001 for all pairs by Mann Whitney test, Supplementary Table 1). In both the presence and absence of metabolic conversion, 5,6-DPQ showed the highest gametocytocidal potency (Supplementary Table 2). These results confirm that PQ requires metabolic activation to elicit activity against both liver stage parasites and gametocytes; gametocytocidal activity of $\mathrm{OH}-\mathrm{PQm}$ in the in vitro gametocyte setting is also shown to be HLM metabolism-dependent.

To gain further insight, we directly assessed the role of CYP2D6 in OH-PQm activity against gametocytes by performing coupled in vitro metabolism-GC-LUC assays using CYP2D6expressing baculosomes (Fig. 1h). As with HLM, CYP2D6 treatment potentiated $\mathrm{OH}-\mathrm{PQm}$ gametocytocidal activity, with $p<0.05$ for 5,6-DPQ and 6OHPQQI, and $p<0.001$ for all other compounds (Mann Whitney, Supplementary Table 3). However, $\mathrm{OH}-\mathrm{PQm}$ are believed to be the terminal products of primaquine metabolism, so we further investigated these results by blocking CYP2D6 activity with the specific inhibitor paroxetine ${ }^{15}$ (Supplementary Fig. 2) prior to drug in vitro metabolism and GC-LUC assays. Interestingly, CYP2D6 inhibition did not significantly affect $\mathrm{OH}-\mathrm{PQm}$ gametocytocidal activity (Fig. 1h, compare $(+) 2 \mathrm{D} 6$ and (+)2D6 + Paroxetine); conversely, PQ activity decreased $(p<0.05)$ as expected, reverting towards the levels observed in control samples without CYP2D6 (Mann Whitney, Supplementary Table 4). Overall, these results show that OH-PQm activity is greatly enhanced by baculosome metabolic component(s), however, the observed potentiation is independent of CYP2D6 activity.

These results prompted us to hypothesise that OH-PQm might be direct substrates of CPR, the CYPs redox partner required for electron transfer from $\mathrm{NAPDH}^{16}$, an intrinsic (and required) component of HLM and CYP2D6 baculosome preparations. We therefore measured initial reaction rates of human recombinant CPR (huCPR) ${ }^{17}$ with PQ and OH-PQm (Supplementary Fig. 5) and generated the apparent steady-state kinetics for each compound (Supplementary Table 5). These analyses revealed that $\mathrm{OH}-\mathrm{PQm}$ are indeed $\mathrm{CPR}$ substrates; conversely, kinetic parameters showed parental PQ to be a poor CPR substrate, as predictable from its structure, and hence it was not included in the subsequent analysis. We then tested the gametocytocidal ability of $\mathrm{OH}-\mathrm{PQm}$ following incubation with huCPR and observed that, akin to HLM and the baculosome treatment, in the presence of huCPR only, the gametocytocidal activity of all metabolites was significantly increased (Fig. 1i, $p<0.001$ for all compounds, Mann Whitney, Supplementary Table 6). This effect was completely prevented when the assay was performed in the absence of $\mathrm{NADP}^{+}$, required for the production of the essential cofactor NADPH by the reaction components (see "Methods") (Fig. 1i, compare (+)huCPR and (+)huCPR-No $\mathrm{NADP}^{+}$), confirming that huCPR catalysis mediates $\mathrm{OH}-\mathrm{PQm}$ gametocytocidal activity. Cognisant of the putative role of $\mathrm{H}_{2} \mathrm{O}_{2}$-producing redox-active $\mathrm{PQ}$ metabolites in $\mathrm{PQ}$ haemolytic toxicity in G6PDH-deficient individuals ${ }^{3,18}$, we indirectly assessed the contribution of reactive oxygen species to the gametocytocidal activity of huCPR-treated PQ metabolites by using sodium pyruvate as a $\mathrm{H}_{2} \mathrm{O}_{2}$ scavenger ${ }^{19}$. As shown in Fig. 1i (compare huCPR and huCPR + pyruvate), the presence of pyruvate abrogated $\mathrm{OH}-\mathrm{PQm}$ gametocytocidal activity $(p<0.01$; Mann Whitney, Supplementary Table 7). These results establish the need for huCPR catalytic activity for $\mathrm{OH}-\mathrm{PQm}$ mechanism of action and point to a direct role for huCPR as a redox cycler of $\mathrm{OH}-\mathrm{PQm}$ 
Redox cycling of PQ metabolites generates gametocytocidal $\mathbf{H}_{2} \mathrm{O}_{2}$. To further confirm this observation, we directly measured $\mathrm{H}_{2} \mathrm{O}_{2}$ generation during drug incubation with human CPR (huCPR). To this end, $\mathrm{O}_{2}$ consumption during incubations was recorded using a closed $\mathrm{O}_{2}$ electrode and $\mathrm{H}_{2} \mathrm{O}_{2}$ was quantified via oxygen release after catalase addition. As shown in Fig. 2a, all metabolites, compared to methanol control, elicited $\mathrm{H}_{2} \mathrm{O}_{2}$ production, whereas negligible amounts of $\mathrm{H}_{2} \mathrm{O}_{2}$ were detected when PQ was used as a substrate. When sodium pyruvate was added to CPR reactions, $\mathrm{H}_{2} \mathrm{O}_{2}$ production was completely abolished (Fig. 2b). In addition, we measured $\mathrm{H}_{2} \mathrm{O}_{2}$ production in titration experiments with 5-HPQ as a representative OH-PQm (Supplementary Fig. 5) and observed that as low as $1 \mathrm{nM} 5$-HPQ is able to elicit $\mathrm{H}_{2} \mathrm{O}_{2}$ production. We confirmed $\mathrm{H}_{2} \mathrm{O}_{2}$ involvement in gametocyte killing by directly assessing its production upon HLM and CYP2D6 metabolism of PQ and 5-HPQ and 5,6-DPQ as representative metabolites (Fig. 2c, d and Supplementary Fig. 4 for representative full traces of oxygen content). Collectively, these data clearly demonstrate that huCPR is required for
$\mathrm{OH}-\mathrm{PQm}$ anti-gametocyte activity and that this process occurs through generation of $\mathrm{H}_{2} \mathrm{O}_{2}$, implying a redox cycling, CPRmediated mechanism of parasite death directly attributable to the generation of $\mathrm{H}_{2} \mathrm{O}_{2}$.

$\mathrm{H}_{2} \mathrm{O}_{2}$ production by $\mathrm{PQ}$ in bone marrow. We reasoned that spatial co-localisation of parasite and host-dependent metabolic activating system(s) could account for PQ stage-specificity. For EEFs this association is obvious with parasite residency within the hepatocyte; for gametocytes this is less obvious as circulating gametocytes are rarely in juxtaposition to a potential source of metabolism. However, $P$. vivax and $P$. falciparum gametocytes, including mature stages ${ }^{20,21}$, are sequestered/enriched in the bone marrow $^{22,23}$, which is also endowed with significant P450dependent metabolic capacity ${ }^{24-26}$. To address this possibility, the ability of PQ and OH-PQm to generate $\mathrm{H}_{2} \mathrm{O}_{2}$ in mouse bone marrow cell extracts was investigated. Results in Fig. 2e show that $\mathrm{PQ}$ and $\mathrm{OH}-\mathrm{PQm}$ generated $\mathrm{H}_{2} \mathrm{O}_{2}$ when incubated with
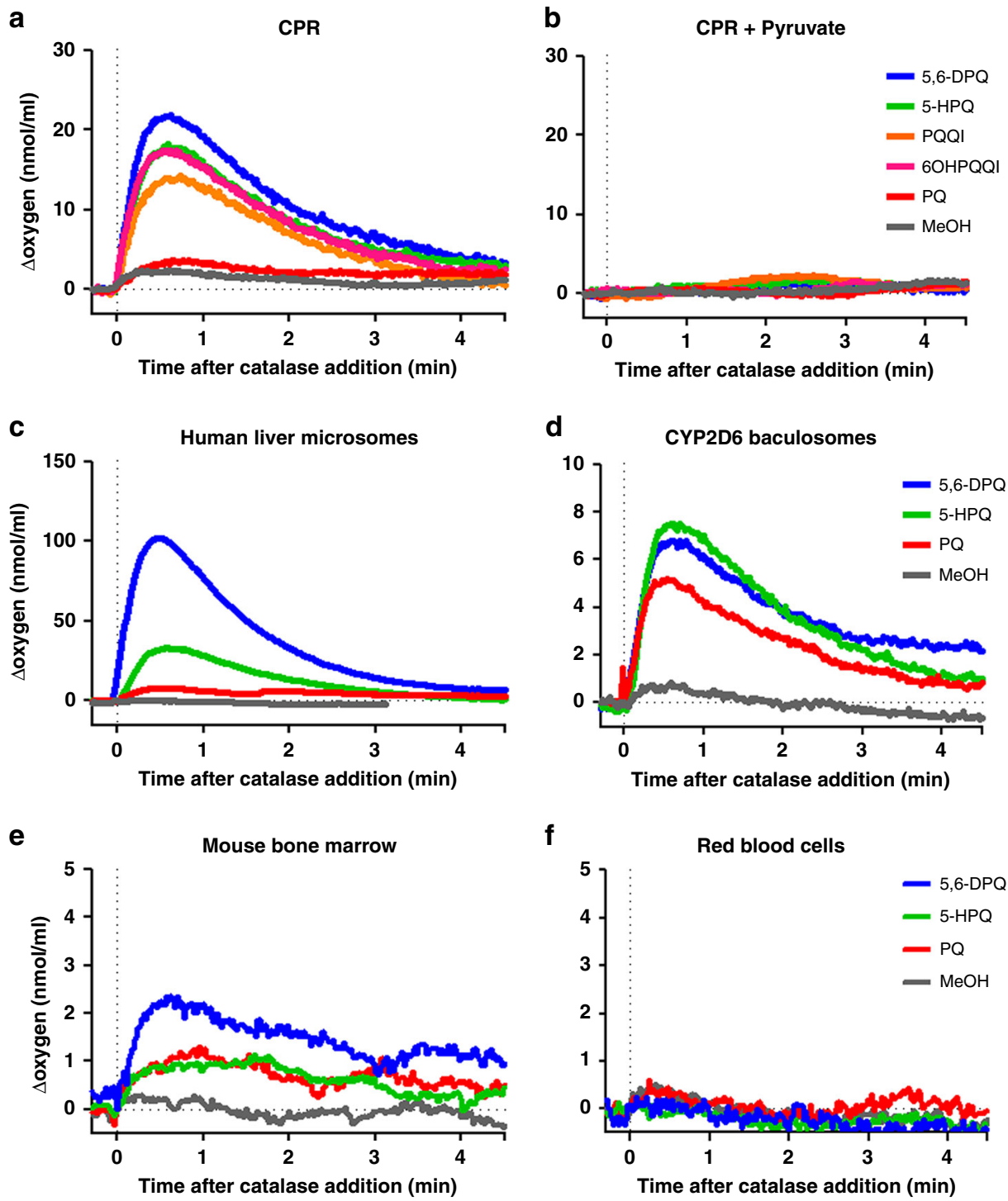

Fig. 2 Metabolism-mediated generation of $\mathrm{H}_{2} \mathrm{O}_{2} \cdot \mathrm{H}_{2} \mathrm{O}_{2}$ production was measured as catalase-mediated oxygen release after compound incubation (30 $\mu \mathrm{M}$ ) with a human CPR, b human CPR + pyruvate, c human liver microsomes, $\mathbf{d}$ CYP2D6-expressing baculosomes, e mouse bone marrow extracts or $\mathbf{f}$ red blood cell extracts. The $x$ axis was adjusted by defining the addition of catalase as $t=0$, and the corresponding $y$ axis value defined as $0 \mathrm{nmol} \mathrm{mL}^{-1}$. The average of two (PQ and 5,6-DPQ) and five (5-HPQ and $\mathrm{MeOH})$ independent measurements are shown 


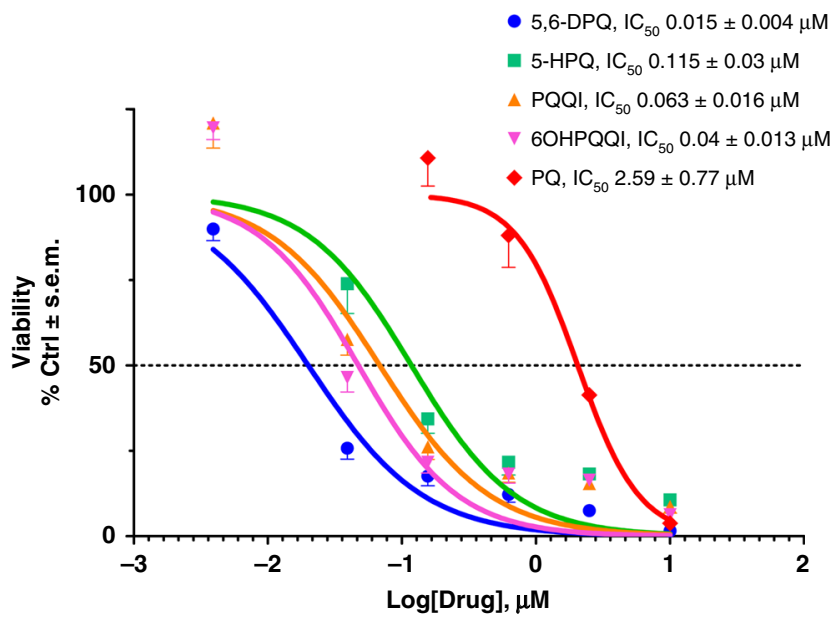

Fig. 3 Dose-response viability of late stage gametocytes treated with $\mathrm{PQ}$ and $\mathrm{OH}-\mathrm{PQm}$ upon reaction with human $\mathrm{CPR}$. Compounds at concentrations ranging from $30 \mu \mathrm{M}$ to $11.7 \mathrm{nM}$ were incubated with human CPR and diluted 1:3 for GC-LUC assays ( $n=2$, each in triplicate). $I C_{50} S$ ( \pm S.E.M.) were calculated from nonlinear regression (curve fit) in GraphPad Prism

bone marrow crude cell extracts, whereas no $\mathrm{H}_{2} \mathrm{O}_{2}$ could be detected with equivalent amount of proteins from red blood cells (to represent the circulating parasite environment) (Fig. 2f). These results support the view that localised $\mathrm{H}_{2} \mathrm{O}_{2}$ generation at specific anatomical sites is responsible for stage-specific parasite killing by PQ metabolites.

PQ-metabolite efficacy at pharmacologically-relevant doses. Next, we determined gametocyte inhibition sensitivity profiles $\left(\mathrm{IC}_{50}\right)$ of $\mathrm{OH}-\mathrm{PQm}$. Dose-response huCPR reactions were performed prior to GC-LUC assays. As shown in Fig. 3, OH-PQm are all active at pharmacologically-relevant nanomolar concentrations, with 5,6-DPQ being the most active with an $\mathrm{IC}_{50}$ of $15 \pm 0.4 \mathrm{nM}$. Conversely, parental PQ shows an $\mathrm{IC}_{50}$ of $2.59 \pm$ $0.77 \mu \mathrm{M}$, in strong agreement with the measured enzyme kinetics. These results support a catalytic mechanism of action for PQ metabolites via CPR-mediated redox cycling that is in line with expected drug metabolite exposure after clinically relevant PQ doses $^{27-29}$.

\section{Discussion}

Our results unveil a two-step biochemical relay underlying PQ mode of action relying on CYP2D6 and its redox partner CPR (Fig. 4). PQ oxidation principally by CYP2D6 generates hydroxylmetabolites whose oxidation to quinoneimine generates $\mathrm{H}_{2} \mathrm{O}_{2}$. Quinoneimines in turn are substrates for CPR reducing activity, thus leading to $\mathrm{H}_{2} \mathrm{O}_{2}$ accumulation which can exert anti-parasitic activity directly through oxidation of protein sulphydryl groups and damage of $\mathrm{Fe}$ - and $\mathrm{FeS}$-containing proteins or through the generation of superoxide and hydroxyl radicals. The intrinsic instability of parent hydroxyl-metabolites prevents identification of all the relevant chemical species in the process. However, it is important to emphasise that our results show that quinoneimine metabolites, considered as stable degradation products or markers for the unstable hydroxylated forms ${ }^{28,29}$, are also substrates for redox cycling activities involved in anti-parasitic action. Direct demonstration of CYP2D6-dependent PQ antimalarial activity against $P$. falciparum liver stages supports clinically-led hypotheses for the essentiality of CYP2D6 for PQ activity ${ }^{8}$.
Significantly, our data also shows that $\mathrm{OH}-\mathrm{PQm}$ exert antimalarial activity against liver parasite stages independently of CYP2D6 (Fig. 2). This finding has significant implications for the design of improved 8-aminoquinolines which retain antimalarial activity but which importantly would not be determinately affected by the CYP2D6 status of the patient.

The described biochemical relay accounts for a unique mode of action (MoA) involving two host enzymes and has implications not only for bioactivation but also for pharmacodynamics. The elucidation of a catalytic (e.g. $1 \mathrm{nM}$ ) MoA for OH-PQm (generating $\mu \mathrm{M}$ levels of $\mathrm{H}_{2} \mathrm{O}_{2}$, Supplementary Fig. 5) explains how single low-dose $\mathrm{PQ}$, down to $0.25 \mathrm{mg} / \mathrm{kg}$, retains transmission blocking ability in clinical settings ${ }^{30}$; importantly, this treatment is also well tolerated in G6PD deficient patients ${ }^{30}$. The emphasis on a host-mediated MoA, not directly involving any parasite targets that are subject to selective pressure, may also provide an explanation for the apparent lack of resistance to PQ in the field; in fact, treatment failure so far has only been linked to CYP2D6 polymorphisms.

These results do not exclude a role for other human host strong reducing enzymes in mediating PQ antimalarial activity. However, we propose that the tissue-specific juxtaposition of CYP2D6 and CPR, in the liver and bone marrow ${ }^{24-26}$, exquisitely explains the susceptibility of liver stages, including hypnozoites, of $P$. falciparum gametocytes, and of $P$. vivax gametocytes and asexual stages, the latter recently shown to be enriched in the bone marrow ${ }^{23}$. Moreover, the results presented accurately mirror the clinical efficacy data in that PQ appears to be more active against gametocytes than liver stages. This observation supports the validity of the in vitro models used here as proxies for in vivo conditions.

Overall, these data provide a framework that will make it possible to test the potential of rationally re-designing PQ analogues that can be activated even against a backdrop of CYP2D6 poor metaboliser status. Furthermore, armed with this knowledge, it will be possible to test if antimalarial activity can ever be divorced from haemotoxicity.

\section{Methods \\ Reagents. All chemical reagents were from Sigma-Aldrich unless otherwise specified.}

Chemical syntheses. Reactions that were air and moisture sensitive were performed under a nitrogen or argon atmosphere. This was achieved with oven dried or flame dried glassware sealed with a rubber septum. Dry nitrogen gas was introduced via a manifold or balloon.

Reactions were stirred using Teflon-coated magnetic stir bars. Organic solutions were concentrated using a Büchi rotary evaporator with a diaphragm vacuum pump. Anhydrous solutions and sensitive liquids were transferred via syringe.

All reagents were purchased from Sigma Aldrich or Alfa Aesar and were used without purification unless otherwise indicated. 5,6-dimethoxy-8-nitroquinoline was obtained from WuXi AppTec.

${ }^{1} \mathrm{H}$ NMR spectra were measured on a Brucker AMX400 (400 MHz) nuclear magnetic resonance spectrometer. Solvents are indicated in the text. The data for ${ }^{1} \mathrm{H}$ NMR spectra are reported as follows: chemical shifts were described in parts per million $(\delta, \mathrm{ppm})$ downwards from an internal reference of trimethylsilane. ${ }^{13} \mathrm{C}$ NMR spectra were measured on a Brucker AMX400 $(100 \mathrm{MHz})$ and are reported in terms of chemical shift $(\delta, \mathrm{ppm})$ relative to residual solvent peak. MS and High resolution mass spectrometry (HRMS) were recorded on a VG analytical 7070E machine, Frisons TRIO spectrometers or Agilent QTOF 7200 using chemical ionisation (CI) or electron ionisation (EI). Micromass LCT mass spectrometer used electron spray ionisation (ESI).

The synthesis of metabolites was based on modifications of literature procedures (Supplementary Fig. 6) ${ }^{31,32}$ as described below.

For the synthesis of 5,6-dimethoxyquinolin-8-amine ${ }^{31}$ 5,6-dimethoxy-8nitroquinoline ( $2 \mathrm{~g}, 8.54 \mathrm{mmol}$ ) was dissolved in Tetrahydrofuran (THF, $20 \mathrm{~mL}$ ). A solution of sodium hypophosphite $(6 \mathrm{~g}, 68.32 \mathrm{mmol})$ in $10 \mathrm{~mL}$ water was added to the reaction. The flask was purged with nitrogen. $10 \%$ palladium on carbon $(0.7 \mathrm{~g})$ was added to the reaction mixture and purged with nitrogen. The reaction was allowed to stir vigorously for $10 \mathrm{~min}$. A celite pad was prepared and the reaction mixture was filtered through the pad of celite and washed through with $20 \mathrm{~mL}$ 


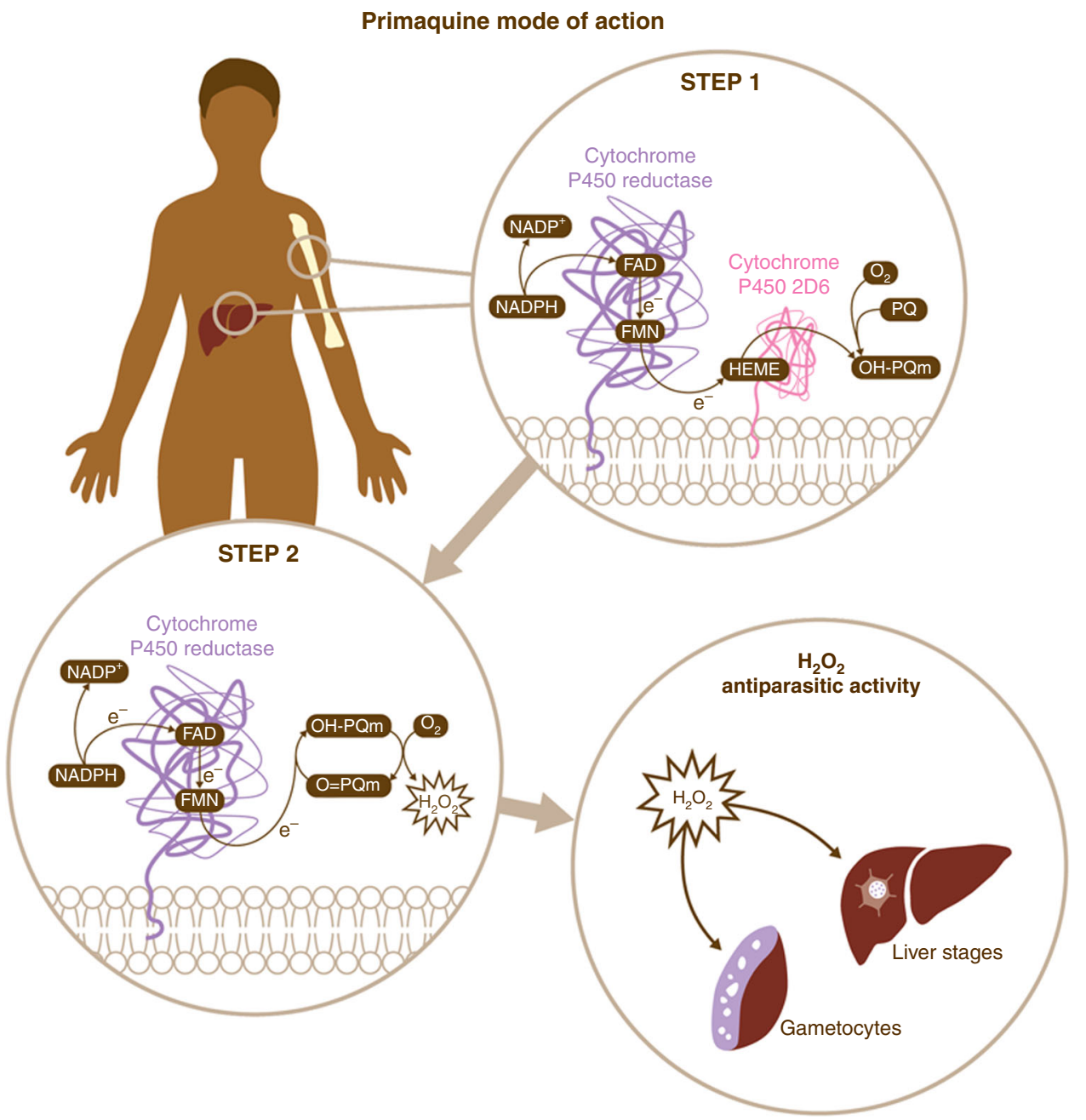

Fig. 4 Schematic representation of primaquine mode of action. The results presented in this work support a two-step biochemical relay mechanism for PQ mode of action. In Step 1, PQ is converted into hydroxylated metabolites (OH-PQm) through the CPR/CYP2D6 metabolic complex. In Step 2, metabolites then undergo spontaneous oxidation to quinoneimines $(\mathrm{O}=\mathrm{PQm})$ with concomitant generation of $\mathrm{H}_{2} \mathrm{O}_{2}$. Human $\mathrm{CPR}$ then receives two electrons from $\mathrm{NADPH}$ and orchestrates one-electron transfers via FAD/FMN cofactors to quinoneinimes, thus reducing them back to the hydroxyl forms and perpetuating a catalytic cycle which brings about $\mathrm{H}_{2} \mathrm{O}_{2}$ accumulation at sites of metabolic transformation (liver, bone marrow and possibly others). Plasmodium parasites present at these locations are then killed by $\mathrm{H}_{2} \mathrm{O}_{2}$ action

chloroform. Sodium hydroxide $(2 \mathrm{M}, 50 \mathrm{~mL})$ was added to the filtrate. The filtrate was extracted with chloroform $(3 \times 100 \mathrm{~mL})$ and the combined organic extracts were washed with water $(2 \times 50 \mathrm{~mL})$, dried over magnesium sulphate and filtered. The chloroform was removed under reduced pressure to obtain the pure product $(1.72 \mathrm{~g}, 98.5 \%)$ as a red-orange solid; $R_{\mathrm{f}}=0.15,30 \%$ ethyl acetate in hexane; ${ }^{1} \mathrm{H}$ NMR $\left(400 \mathrm{MHz}, \mathrm{CDCl}_{3}\right) \delta 8.62(\mathrm{dd}, J=4.1,1.6 \mathrm{~Hz}, 1 \mathrm{H}), 8.33(\mathrm{dd}, J=8.5,1.6 \mathrm{~Hz}$, $1 \mathrm{H}), 7.35(\mathrm{dd}, J=8.5,4.1 \mathrm{~Hz}, 1 \mathrm{H}), 6.73(\mathrm{~s}, 1 \mathrm{H}), 4.87(\mathrm{~s}, 2 \mathrm{H}), 3.96(\mathrm{~s}, 3 \mathrm{H})$ and $3.89(\mathrm{~s}, 3 \mathrm{H}) ;{ }^{13} \mathrm{C}$ NMR $\left(100 \mathrm{MHz}, \mathrm{CDCl}_{3}\right) \delta 149.6,145.6,141.5,133.8,133.2,129.9$, 124.5, 121.6, 99.1, 61.6 and 56.8; IR $v_{\max }$ (neat)/ $/ \mathrm{cm}^{-1} 3443,3337(\mathrm{NH}), 3192(\mathrm{CH})$ and $1623(\mathrm{C}=\mathrm{C})$; HRMS calculated for $\mathrm{C}_{11} \mathrm{H}_{12} \mathrm{~N}_{2} \mathrm{O}_{2}[\mathrm{M}+\mathrm{H}]^{+} 205.0972$ found 205.0977.

For the synthesis of 4-bromo-1-phthalimidopentane, potassium phthalimide $(10 \mathrm{~g}, 53.99 \mathrm{mmol})$ was dissolved in acetone. 1,4-Dibromopentane $(9.57 \mathrm{~mL}$, $70.19 \mathrm{mmol}$ ) was added to the mixture which was heated to reflux for $24 \mathrm{~h}$. The reaction was cooled and filtered. The acetone was removed under reduced pressure and the crude product was purified via flash chromatography resulting in $(14.62 \mathrm{~g}$ $91 \%)$ a clear light yellow oil. $R_{\mathrm{f}}=0.43,20 \%$ ethyl acetate in hexane; ${ }^{1} \mathrm{H}$ NMR $(400$ $\left.\mathrm{MHz}, \mathrm{CDCl}_{3}\right) \delta 7.88-7.81(\mathrm{~m}, 2 \mathrm{H}), 7.76-7.70(\mathrm{~m}, 2 \mathrm{H}), 4.22-4.10(\mathrm{~m}, 1 \mathrm{H}), 3.72$ $(\mathrm{dd}, J=8.5,4.7 \mathrm{~Hz}, 2 \mathrm{H}), 2.02-1.74(\mathrm{~m}, 4 \mathrm{H})$ and $1.70(\mathrm{~d}, J=6.7 \mathrm{~Hz}, 3 \mathrm{H}) ;{ }^{13} \mathrm{C}$ NMR $\left(100 \mathrm{MHz}, \mathrm{CDCl}_{3}\right) \delta 168.4,134.1,132.1,123.3,50.6,38.1,37.2,27.1$ and 26.5; HRMS Calculated for $\mathrm{C}_{13} \mathrm{H}_{14} \mathrm{BrNO}_{2}[\mathrm{M}+\mathrm{H}]^{+} 296.0281$ found 296.0280 . 5,6-Dimethoxy-8-aminoquinoline ( $500 \mathrm{mg}, 2.45 \mathrm{mmol}$ ) was added to a dry $50 \mathrm{~mL}$ two neck flask along with a dry magnetic bar. A dry condenser and equilibrating dropping funnel were attached to the flask and the second neck was sealed with a rubber septum. The system was purged with dry argon and sealed with a balloon attached to the dropping funnel. 1-Phthalimido-4-bromopentane (942.6 mg, 3.18 $\mathrm{mmol}$ ) was added directly to the reaction via syringe and the reaction was then heated to $150^{\circ} \mathrm{C}$ to produce a dark paste. Triethylamine ( $444 \mu \mathrm{L}, 3.18 \mathrm{mmol}$ ) was added to the reaction via the dropping funnel over a $1.5 \mathrm{~h}$ period. The reaction was left to stir for a further $1.5 \mathrm{~h}$. Additional 1-phthalimido-4-bromopentane $(1.23 \mathrm{~g}, 4.16 \mathrm{mmol})$ was added directly to the reaction via syringe. Triethylamine $(290.3 \mu \mathrm{L}, 2.08 \mathrm{mmol})$ was added to the reaction via the dropping funnel over $30 \mathrm{~min}$. The reaction was left to stir for a further $2 \mathrm{~h}$. 1-Phthalimido-4bromopentane $(235.7 \mathrm{mg}, 795.7 \mu \mathrm{mol})$ was added to the reaction directly via syringe. Triethylamine $(122.9 \mu \mathrm{L}, 881.4 \mu \mathrm{mol})$ was added to the reaction via the dropping funnel over $30 \mathrm{~min}$. The reaction was left to stir for a further $2 \mathrm{~h}$ and monitored by thin layer chromatography (TLC). The reaction was cooled, diluted with acetone and filtered. The acetone was removed, resulting in a dark oil which was dissolved in chloroform $(100 \mathrm{~mL})$. The organic layer was washed with water $(3 \times 50 \mathrm{~mL})$, dried over magnesium sulphate and filtered. The crude product was pre-absorbed onto silica and purified via flash chromatography to obtain the product $(790.5 \mathrm{mg}, 77 \%)$ as a yellow oil; $R_{\mathrm{f}}=0.3,30 \%$ Ethyl Acetate in Hexane; ${ }^{1} \mathrm{H}$ $\operatorname{NMR}\left(400 \mathrm{MHz}, \mathrm{CDCl}_{3}\right) \delta 8.53(\mathrm{dd}, J=4.1,1.6 \mathrm{~Hz}, 1 \mathrm{H}), 8.27(\mathrm{dd}, J=8.5,1.6 \mathrm{~Hz}$ $1 \mathrm{H}), 7.84-7.78(\mathrm{~m}, 2 \mathrm{H}), 7.72-7.66(\mathrm{~m}, 2 \mathrm{H}), 7.33(\mathrm{dd}, J=8.5,4.1 \mathrm{~Hz}, 1 \mathrm{H}), 6.41(\mathrm{~s}$, $1 \mathrm{H}), 5.89(\mathrm{~d}, J=6.4 \mathrm{~Hz}, 1 \mathrm{H}), 3.99(\mathrm{~s}, 3 \mathrm{H}), 3.86(\mathrm{~s}, 3 \mathrm{H}), 3.74(\mathrm{t}, J=7.1 \mathrm{~Hz}, 2 \mathrm{H})$, 3.71-3.63 $(\mathrm{m}, 1 \mathrm{H}), 1.99-1.62(\mathrm{~m}, 4 \mathrm{H})$ and $1.30(\mathrm{~d}, J=6.3 \mathrm{~Hz}, 3 \mathrm{H}) ;{ }^{13} \mathrm{C} \mathrm{NMR}$ $\left(100 \mathrm{MHz}, \mathrm{CDCl}_{3}\right) \delta 168.6,150.0,144.8,141.9,134.0,133.7,132.2,131.3,129.8$, $124.6,123.3,121.7,94.3,61.6,57.0,48.1,38.1,34.1,25.5$ and 20.8; IR $v_{\max }$ (neat)/ $\mathrm{cm}^{-1} 3390(\mathrm{NH}), 2964,2936(\mathrm{CH})$ and $1707(\mathrm{C}=\mathrm{O})$; HRMS Calculated for $\mathrm{C}_{24} \mathrm{H}_{25} \mathrm{~N}_{3} \mathrm{O}_{4}[\mathrm{M}+\mathrm{H}]^{+} 420.1923$ found 420.1922 . 
For the synthesis of 5,6 dimethoxy primaquine ${ }^{31}, 5,6$ dimethoxy-phthaloyl primaquine $(790.5 \mathrm{mg}, 1.88 \mathrm{mmol}$ ) was dissolved in $25 \mathrm{ml}$ of ethanol in a $50 \mathrm{~mL}$ round bottom, a condenser was attached and the system was purged with nitrogen. Sixty-five percent hydrazine monohydrate $(465.5 \mu \mathrm{L}, 6.22 \mathrm{mmol})$ was added to the reaction and refluxed $\left(\right.$ at $\left.100{ }^{\circ} \mathrm{C}\right)$ for $6 \mathrm{~h}$. A solid precipitate was observed. The reaction was cooled and filtered. The ethanol was removed and 30\% potassium hydroxide $(100 \mathrm{~mL})$ was added to the residue. The mixture was extracted with diethyl ether $(3 \times 50 \mathrm{~mL})$. The combined organic layers were washed with water $(50 \mathrm{~mL})$, dried over magnesium sulphate and filtered. A solution of $89 \%$ phosphoric acid $(187 \mu \mathrm{L}, 2.73 \mathrm{mmol})$ in ethanol $(5 \mathrm{~mL})$ was added drop wise to the ether solution. A red/orange precipitate was observed. The solvent was removed under vacuo and the precipitate was recrystallised with ethanol to obtain an orange/red solid (501 mg, 92\%); ${ }^{1} \mathrm{H}$ NMR (400 MHz, DMSO) $\delta 8.57$ (dd, $J=4.1$, $1.5 \mathrm{~Hz}, 1 \mathrm{H}), 8.23$ (dd, $J=8.5,1.5 \mathrm{~Hz}, 1 \mathrm{H}), 7.47(\mathrm{dd}, J=8.5,4.1 \mathrm{~Hz}, 1 \mathrm{H}), 6.55(\mathrm{~s}$, $1 \mathrm{H}), 6.02(\mathrm{~s}, 2 \mathrm{H}), 3.94(\mathrm{~s}, 3 \mathrm{H}), 3.75(\mathrm{~s}, 3 \mathrm{H}), 3.80-3.71(\mathrm{~m}, 1 \mathrm{H}), 2.80(\mathrm{t}, J=6.3$ $\mathrm{Hz}, 2 \mathrm{H}), 1.79-1.55(\mathrm{~m}, 4 \mathrm{H})$ and $1.23(\mathrm{~d}, J=6.2 \mathrm{~Hz}, 3 \mathrm{H}) ;{ }^{13} \mathrm{C} \mathrm{NMR}(100 \mathrm{MHz}$, DMSO) $\delta 149.8,144.6,141.5,132.6,130.0,129.2,123.8,122.0,94.0,60.9,56.5,46.9$, 38.9, 33.1, 24.1 and 20.4; HRMS Calculated for $\mathrm{C}_{24} \mathrm{H}_{25} \mathrm{~N}_{3} \mathrm{O}_{4}[\mathrm{M}+\mathrm{H}]^{+} 420.1923$ found 420.1922 .

Two general procedures were used for demethylation, as indicated. The general procedure 1 was based on a modified procedure of Allahyari et al. ${ }^{32}$. Ten milligram of 5,6 dimethoxy primaquine was dissolved in $1 \mathrm{~mL}$ of $48 \%$ hydrogen bromide solution (ca $6 \mathrm{M}$ ) and sealed under argon in a sealed tube. The reaction was heated to $120^{\circ} \mathrm{C}$ on a pre-heated mantle for 20 mins. Under a flow of nitrogen, $5 \mathrm{~mL}$ of water was added and the product(s) were purified via HPLC. For the general procedure 2, $10 \mathrm{mg}$ of 5,6 dimethoxy primaquine was dissolved in $1 \mathrm{~mL}$ of $48 \%$ hydrogen bromide solution and the solution was allowed to stir for $6 \mathrm{~h}$. Excess reagent was removed under vacuum to give a brown solid that was stored under nitrogen.

HPLC conditions were as follows: a Phenomenex Jupiter Proteo 90 A column, $250 \times 10 \mathrm{~mm}, 10$ Micron was used for purification using a gradient system based on the following conditions; Initial (time 0 ) solvent mix 5\% acetonitrile, $95 \% 0.05 \%$ trifluoracetic acid (TFA) in water; 20 mins, $25 \%$ acetonitrile, $75 \% 0.05 \%$ TFA in water; $20.10 \mathrm{~min} 5 \%$ acetonitrile, $95 \% 0.05 \%$ TFA in water; flow rate was $5 \mathrm{ml} \mathrm{min}^{-1}$.

All samples were dried by blowing off the solvent under a flow of nitrogen 5,6dihydroxyprimaquine (5,6-DPQ) was prepared according to general procedure 2; this compound was very unstable rapidly oxidising to 5-hydroxy quinoneimine (5-HPQ) in solutions exposed to air. (MS for $\mathrm{C}_{14} \mathrm{H}_{19} \mathrm{~N}_{3} \mathrm{O}_{2}[\mathrm{M}+\mathrm{H}]{ }^{+}$found 262.33). The metabolite was stored under nitrogen in a sealed tube.

For the synthesis of 5-hydroxy primaquine (5-HPQ) general procedure 1 along with HPLC purification and drying was used (see HPLC conditions above). 5-Hydroxy 6-Methoxy Primaquine $=10.06 \mathrm{~min}$. The 5-hydroxy 6-methoxy primaquine was very unstable as it readily oxidises to the quinoneimine form. LCMS has shown that this is present within the reaction mixture, however, upon isolation and re-evaluation using the HPLC conditions, the retention time at 10.06 min corresponding to the product is no longer observed. Once the quinoneimine has formed from 5-OH primaquine, it is readily converted to the 6-hydroxy form (6OHPQQI; $\mathrm{Rt}=12.55$ mins) by a demethylation reaction (through reaction with water).

For the synthesis of Primaquine quinone-imine (PQQI), general procedure 1 provides the -hydroxy primaquine which can be allowed to oxidise to the quinoneimine in aqueous solution. HPLC purification and drying (see above) were used for isolation. The quinoneimine was purified with two HPLC purification runs. Retention time: $=7.76 \mathrm{~min}{ }^{1} \mathrm{H}$ NMR $\left(500 \mathrm{MHz}, \mathrm{D}_{2} \mathrm{O}\right) \delta 9.03(\mathrm{~d}, J=3.6 \mathrm{~Hz}$, $1 \mathrm{H}), 8.59(\mathrm{~d}, J=6.6 \mathrm{~Hz}, 1 \mathrm{H}), 7.96(\mathrm{dd}, J=8.0,4.8 \mathrm{~Hz}, 1 \mathrm{H}), 6.99(\mathrm{~s}, 1 \mathrm{H}), 4.22(\mathrm{~s}$, $3 \mathrm{H}), 3.07(\mathrm{t}, J=7.6 \mathrm{~Hz}, 3 \mathrm{H}), 2.11-1.95(\mathrm{~m}, 3 \mathrm{H}), 1.88-1.72(\mathrm{~m}, 3 \mathrm{H})$ and $1.58(\mathrm{~d}$, $J=6.5 \mathrm{~Hz}, 3 \mathrm{H})$; MS for $\mathrm{C}_{15} \mathrm{H}_{19} \mathrm{~N}_{3} \mathrm{O}_{2}[\mathrm{M}+\mathrm{H}]^{+}$found 274.38 .

For the synthesis of 6-hydroxy primaquine quinone imine (6OHPQQI), general procedure 2 along with HPLC purification and drying (see section 1.1.3) was used. This compound could also be produced by reaction of the 6-methoxy quinoneimine in aqueous solution followed by HPLC purification. (See analysis below) Retention time: $=12.55 \mathrm{~min} .{ }^{1} \mathrm{H}$ NMR $\left(500 \mathrm{MHz}, \mathrm{D}_{2} \mathrm{O}\right) \delta 8.86(\mathrm{dd}, J=4.9$, $1.7 \mathrm{~Hz}, 1 \mathrm{H}), 8.40(\mathrm{dd}, J=7.9,1.7 \mathrm{~Hz}, 1 \mathrm{H}), 7.75(\mathrm{dd}, J=7.9,4.9 \mathrm{~Hz}, 1 \mathrm{H}), 6.12(\mathrm{~s}, 1$ $\mathrm{H}), 4.11(\mathrm{dd}, J=13.1,6.7 \mathrm{~Hz}, 1 \mathrm{H}), 3.05(\mathrm{t}, J=7.4 \mathrm{~Hz}, 2 \mathrm{H}), 1.92-1.74(\mathrm{~m}, 4 \mathrm{H})$ and $1.42(\mathrm{~d}, J=6.5 \mathrm{~Hz}, 3 \mathrm{H}) ; \mathrm{MS}$ for $\mathrm{C}_{14} \mathrm{H}_{17} \mathrm{~N}_{3} \mathrm{O}_{2}[\mathrm{M}+\mathrm{H}]^{+}$found 260.35 .

In vitro metabolism and redox cycling reactions. Human liver microsomes (HLM, BD Biosciences) and CYP2D6-expressing baculosomes from the Vivid CYP450 kit (Life Technologies) were used for compound metabolic conversions as per manufacturer's instructions with minor modifications. For HLM, compounds ( $30 \mu \mathrm{M}$ final concentration) were incubated in the presence of NAPDH Regeneration System Solution A and B (BD Biosciences) at $37^{\circ} \mathrm{C}$ for $2 \mathrm{~h}$ in a total volume of $100 \mu$ of phosphate reaction buffer. For CYP2D6 baculosomes reaction, a $2 \times$ master mix $(50 \mu \mathrm{l})$ was prepared containing reaction buffer, baculosomes, regeneration system and $\mathrm{NADP}^{+}$(all from Life technologies). Compounds $(30 \mu \mathrm{M}$ final concentration) were prepared in $40 \mu \mathrm{l}$ reaction buffer containing $\mathrm{NADP}^{+}$as per kit protocol. The total volume was brought to $100 \mu \mathrm{l}$ with reaction buffer and reactions incubated at $37^{\circ} \mathrm{C}$ for $2 \mathrm{~h}$. For CYP2D6 inhibition, we first determined paroxetine inhibitory profile using Vivid CYP2D6 Blue kit (Life Technologies) according to manufacturer's instructions. For gametocytocidal assays, master mixes without compounds were pre-incubated with paroxetine $(10 \mu \mathrm{M})$ for $15 \mathrm{~min}$ at $37^{\circ} \mathrm{C}$ before addition of compounds and further incubation $37^{\circ} \mathrm{C}$ for $2 \mathrm{~h}$. Recombinant huCPR ${ }^{17}$ was used for in vitro redox cycling of compounds. Reactions were performed as described above with minor modifications. A master mix without baculosomes was prepared as above; huCPR were added in $10 \mu \mathrm{l}$ of reaction buffer ( $200 \mathrm{nM}$ final concentration) and reactions started by adding $40 \mu \mathrm{l}$ of compound/ $\mathrm{NADP}^{+}$mix. For $\mathrm{H}_{2} \mathrm{O}_{2}$ scavenging, sodium pyruvate $(10 \mathrm{mM})$ was used, without pre-incubation. All experiments contained control reactions with solvent $(\mathrm{MeOH}$ : water 50:50) only. After incubations, reaction mixes were spun down, supernatants collected, diluted 2:3 and seeded into 96-well plates for GC-LUC assay.

Parasite culture, drug treatments and gametocyte luciferase assay (GC-LUC) A P. falciparum $3 \mathrm{D} 7 \mathrm{~A}^{33}$ transgenic derivative $3 D 7$ elo1-pfs 16-CBG99 was used 14,34 specifically expressing the CBG99 luciferase in gametocytes. Parasites were cultured ${ }^{35}$ in human $0+$ erythrocytes at $5 \%$ haematocrit under $5 \% \mathrm{CO}_{2}, 2 \% \mathrm{O}_{2}, 93 \%$ $\mathrm{N}_{2}$. Cultures were grown in complete medium (CM) containing RPMI 1640 medium (Gibco) supplemented with $25 \mathrm{mM}$ Hepes (VWR), $50 \mu \mathrm{g} \mathrm{mL}^{-1}$ hypoxanthine, $0.25 \mathrm{mM} \mathrm{NaHCO}_{3}, 50 \mu \mathrm{g} \mathrm{mL}^{-1}$ gentamicin sulfate, and $10 \%$ pooled heat inactivated $\mathrm{AB}$ + human serum. Gametocyte viability was evaluated by the GCLUC assay ${ }^{14,34}$. Parasites were quickly harvested in $2 \times \mathrm{CM}$ before addition to 96-well plates containing control, CYP2D6- or huCPR-treated compounds $(10 \mu \mathrm{M}$ parental compound final concentration) in aqueous solution and incubatied at $37^{\circ} \mathrm{C}$ for $72 \mathrm{~h}$. Drug-treated gametocytes were then transferred to 96 -well white plate; D-Luciferin, $1 \mathrm{mM}$ in $0.1 \mathrm{M}$ citrate buffer $\mathrm{pH} 5.5$ (Promega), was added in a 1:1 ratio and luminescence measurements were recorded after $10 \mathrm{~min}$ on a FLUOstar Omega plate reader (BMG Labtech). Viability was expressed as \% viability as compared to solvent treated controls.

Liver stages assay. Micropatterned hepatocyte-fibroblast co-cultures were established as previously described ${ }^{12,36}$. Briefly, soft lithography techniques were used to pattern rat tail type I collagen (Corning) into $500 \mu \mathrm{m}$ diameter islands on the surface of glass bottom 96-well plates. Cryopreserved primary human hepatocytes (Bioreclamation IVT) were thawed and pelleted through centrifugation at $100 \mathrm{~g}$ for $6 \mathrm{~min}$, assessed for viability using trypan blue exclusion (70-90\% viability) and 10,000 hepatocytes were seeded onto the collagen islands in serum-free DMEM (Dulbecco's Modified Eagle's medium) with $1 \%$ Penstrep. Two to three hours later, cells were washed with DMEM containing $1 \%$ Penstrep, and media was replaced with hepatocyte culture media. The following day, each well was infected with 70,000 fresh $P$. falciparum sporozoites. Three hours later, cultures were washed with DMEM containing 3\% Penstrep and 0.1\% Fungizone, and 7000 3T3 J2 mouse fibroblasts were added to establish the co-culture. Drug was administered during daily media changes for 3 days. The impact on hepatocyte infection was measured by enumeration of exoerythrocytic forms on day 3.5 post infection, through staining for PfHSP70 and visualisation with a Nikon Eclipse Ti fluorescent microscope.

\section{Determination of oxygen consumption and $\mathrm{H}_{2} \mathrm{O}_{2}$ production. Oxygen con-} sumption and $\mathrm{H}_{2} \mathrm{O}_{2}$ production measurements were performed using the $\mathrm{Oxy}-$ therm system and $\mathrm{O}_{2}$ View software package v.2.06 (Hansatech Instruments Ltd). Compounds ability to generate hydrogen peroxide after in vitro metabolism or huCPR reaction, in the presence of regeneration system or $100 \mu \mathrm{M} \mathrm{NADPH}$ as indicated, was assessed indirectly by measuring catalase-mediated oxygen release. Once the kinetic trace for oxygen concentration within the mixture had reached a plateau for at least $3 \mathrm{~min}$, catalase (from bovine liver, prepared in $50 \mathrm{mM}$ potassium phosphate buffer, $\mathrm{pH} 7.0$; final assay concentration $10 \mu \mathrm{g} \mathrm{ml}^{-1}$ ) was added and data recorded for a further $6 \mathrm{~min}$. Oxygen concentration was recorded as nmo $\mathrm{mL}^{-1}$. To allow for easier comparison of individual traces, the $x$ axis was adjusted by defining the addition of catalase as $t=0$, and the corresponding $y$ axis value defined as $0 \mathrm{nmol} \mathrm{mL}^{-1}$.

For bone marrow experiments, femurs were dissected from mice following schedule 1 procedure. The schedule 1 procedure was undertaken with local (LSTM and UoL Animal Welfare Ethics Review Boards) and national (Home Office licence) authorisation. Bone marrow cells were flushed out with cold Ringer's solution pH $7.4\left(125 \mathrm{mM} \mathrm{NaCl}, 1.5 \mathrm{mM} \mathrm{CaCl}, 5 \mathrm{mM} \mathrm{KCl}, 0.8 \mathrm{mM} \mathrm{Na}_{2} \mathrm{HPO}_{4}\right)$ using $2 \mathrm{ml}$ syringe connect with a 25GA needle. The bone marrow cells were washed twice and resuspended with cold Ringer's solution. Cells were lysed by sonication and the protein concentration of crude extracts measured. Oxygen measurements were performed at $37^{\circ} \mathrm{C}$ in $0.4 \mathrm{ml}$ samples containing Ringer's solution $\mathrm{pH} 7.4,8.5 \mathrm{mg} \mathrm{ml}^{-1}$ bone marrow extracts, $1 \mathrm{X}$ regeneration system (Thermo Scientific), $30 \mu \mathrm{M}$ PQ metabolites, $30 \mu \mathrm{M} \mathrm{NADP}^{+}$. The assay mixture without $\mathrm{NADP}^{+}$was pre-incubated in the Oxytherm's chamber at $37^{\circ} \mathrm{C}$ while recording oxygen content. Then, the reaction was initiated by addition of $\mathrm{NADP}^{+}$ After $30,10 \mu \mathrm{l}$ of $5 \mathrm{mg} \mathrm{ml}^{-1}$ catalase (prepared in $50 \mathrm{mM}$ potassium phosphate buffer $\mathrm{pH}$ 7.0) was added to release $\mathrm{O}_{2}$ from $\mathrm{H}_{2} \mathrm{O}_{2}$. Experiments with red blood cells were performed as above with same amount of protein extracts.

Steady-state kinetic measurements. Kinetic measurements were determined following Tsukamoto et $\mathrm{al}^{37}$ and the assay conditions were optimised according to Döhr et al. ${ }^{38}$ with minor modifications. Briefly, huCPR kinetics of interaction with 
$\mathrm{PQ}$ and $\mathrm{OH}-\mathrm{PQm}$ were measured as NADPH consumption via recording of change in absorbance at $340 \mathrm{~nm}$ on a microplate spectrophotometer (Thermo Electron Varioskan) at $25^{\circ} \mathrm{C}$. The activity assay of $0.3 \mathrm{ml}$ contained $0.3 \mathrm{M}$ potassium phosphate ( $\mathrm{pH} 7.7$ ), $25 \mathrm{nM}$ huCPR, $100 \mu \mathrm{M} \mathrm{NADPH}$, and various concentrations of primaquine derivatives $(0-200 \mu \mathrm{M} 5-\mathrm{HPQ}, 0-100 \mu \mathrm{M}$ 5,6-DPQ, 0-150 $\mu \mathrm{M}$ PQQI, 0-150 $\mu \mathrm{M} 6 \mathrm{OHPQQI}$, or 0-1000 $\mu \mathrm{M}$ PQ). Reactions were initiated by adding $\mathrm{NADPH}$ to a final concentration of $100 \mu \mathrm{M}$ after equilibrating the assay mixture with all other components at $25^{\circ} \mathrm{C}$ for $2 \mathrm{~min}$. Data were recorded every $5 \mathrm{~s}$ over $4 \mathrm{~min}$. The Michaelis-Menten equation was used to determine $K_{\mathrm{m}}$ and $k_{\text {cat }}$ values.

Statistics. Statistical analyses were done using GraphPad Prism version 5.04 and version 7 software (GraphPad Software, San Diego, California, USA, www.graphpad.com). Significance was calculated by two-tailed Mann Whitney test. One-way or two-way ANOVA was used as appropriate. Extended statistics tables for each analysis are provided as Additional Information.

Reporting summary. Further information on research design is available in the Nature Research Reporting Summary linked to this article.

\section{Data availability}

The source data underlying Figs. 1a, 2a-d, 6d, h and 7c and Supplementary Figs. 1a and $5 \mathrm{~d}$ are provided as a Source Data file.

Received: 14 September 2018 Accepted: 2 July 2019

Published online: 19 July 2019

\section{References}

1. Ashley, E. A., Recht, J. \& White, N. J. Primaquine: the risks and the benefits. Malar. J. 13, 418 (2014).

2. Marcsisin, S. R., Reichard, G. \& Pybus, B. S. Primaquine pharmacology in the context of CYP 2D6 pharmacogenomics: current state of the art. Pharm. Ther. 161, 1-10 (2016).

3. Tarlov, A. R., Brewer, G. J., Carson, P. E. \& Alving, A. S. Primaquine sensitivity: glucose-6-phosphate dehydrogenase deficiency: an inborn error of metabolism of medical and biological significance. Arch. Intern. Med. 109, 209-234 (1962).

4. Strother, A., Fraser, I. M., Allahyari, R. \& Tilton, B. E. Metabolism of 8aminoquinoline antimalarial agents. Bull. World Health Organ. 59, 413-425 (1981).

5. Vásquez-Vivar, J. \& Augusto, O. Hydroxylated metabolites of the antimalarial drug primaquine. Oxidation and redox cycling. J. Biol. Chem. 267, 6848-6854 (1992).

6. Vale, N., Moreira, R. \& Gomes, P. Primaquine revisited six decades after its discovery. Eur. J. Med. Chem. 44, 937-953 (2009).

7. Raphemot, R., Posfai, D. \& Derbyshire, E. R. Current therapies and future possibilities for drug development against liver-stage malaria. J. Clin. Investig. 126, 2013-2020 (2016).

8. Bennett, J. W. et al. Primaquine failure and cytochrome P-450 2D6 in Plasmodium vivax malaria. New Engl. J. Med. 369, 1381-1382 (2013).

9. Ganesan, S., Tekwani, B. L., Sahu, R., Tripathi, L. M. \& Walker, L. A. Cytochrome $\mathrm{P}(450)$-dependent toxic effects of primaquine on human erythrocytes. Toxicol. Appl. Pharmacol. 241, 14-22 (2009).

10. Pybus, B. S. et al. CYP450 phenotyping and accurate mass identification of metabolites of the 8 -aminoquinoline, anti-malarial drug primaquine. Malar. J. 11, 259 (2012).

11. Committee, W. H. O. M. P. A. \& Secretariat Malaria Policy Advisory Committee to the WHO: conclusions and recommendations of September 2012 meeting. Malar. J. 11, 424 (2012).

12. March, S. et al. A microscale human liver platform that supports the hepatic stages of Plasmodium falciparum and vivax. Cell Host Microbe 14, 104-115 (2013).

13. Llerena, A., Dorado, P. \& Peñas-Lledó, E. M. Pharmacogenetics of debrisoquine and its use as a marker for CYP2D6 hydroxylation capacity. Pharmacogenomics 10, 17-28 (2009).

14. Cevenini, L. et al. Multicolor bioluminescence boosts malaria research: quantitative dual-color assay and single-cell imaging in plasmodium falciparum parasites. Anal. Chem. 86, 8814-8821 (2014).

15. Bertelsen, K. M., Venkatakrishnan, K., von Moltke, L. L., Obach, R. S. \& Greenblatt, D. J. Apparent mechanism-based inhibition of human CYP2D6 in vitro by paroxetine: comparison with fluoxetine and quinidine. Drug Metab. Dispos. 31, 289 (2003).

16. Pandey, A. V. \& Sproll, P. Pharmacogenomics of human P450 oxidoreductase. Front. Pharmacol. 5, 103 (2014).
17. Gutierrez, A. et al. Trp-676 facilitates nicotinamide coenzyme exchange in the reductive half-reaction of human cytochrome P450 reductase: properties of the soluble W676 H and W676A mutant reductases. Biochemistry 39, 15990-15999 (2000).

18. Vásquez-Vivar, J. \& Augusto, O. Oxidative activity of primaquine metabolites on rat erythrocytes in vitro and in vivo. Biochem. Pharmacol. 47, 309-316 (1994).

19. Giandomenico, A. R., Cerniglia, G. E., Biaglow, J. E., Stevens, C. W. \& Koch, C. J. The importance of sodium pyruvate in assessing damage produced by hydrogen peroxide. Free Radic. Biol. Med. 23, 426-434 (1997).

20. Aguilar, R. et al. Molecular evidence for the localization of Plasmodium falciparum immature gametocytes in bone marrow. Blood 123, 959 (2014)

21. De Niz, M. et al. Plasmodium gametocytes display homing and vascular transmigration in the host bone marrow. Sci. Adv. 4, eaat3775 (2018).

22. Joice, R. et al. Plasmodium falciparum transmission stages accumulate in the human bone marrow. Sci. Transl. Med. 6, 244re245-244re245 (2014).

23. Baro, B. et al. Plasmodium vivax gametocytes in the bone marrow of an acute malaria patient and changes in the erythroid miRNA profile. PLoS Negl. Trop. Dis. 11, e0005365 (2017).

24. Ganousis, L. G., Goon, D., Zyglewska, T., Wu, K. K. \& Ross, D. Cell-specific metabolism in mouse bone marrow stroma: studies of activation and detoxification of benzene metabolites. Mol. Pharmacol. 42, 1118 (1992).

25. Alonso, S. et al. Human bone marrow niche chemoprotection mediated by cytochrome p450 enzymes. Oncotarget 6, 14905-14912 (2015).

26. Zhang, Y. et al. Suppression of cytochrome P450 reductase enhances longterm hematopoietic stem cell repopulation efficiency in mice. PLoS ONE 8 , e69913 (2013)

27. Ward, S. A. et al. Pharmacokinetics of primaquine in man. II. Comparison of acute vs chronic dosage in Thai subjects. Br. J. Clin. Pharm. 19, 751-755 (1985).

28. Potter, B. M. et al. Differential CYP 2D6 metabolism alters primaquine pharmacokinetics. Antimicrob. Agents Chemother. 59, 2380-2387 (2015).

29. Fasinu, P. S. et al. Enantioselective metabolism of primaquine by human CYP2D6. Malar. J. 13, 507 (2014).

30. Bancone, G. et al. Single low dose primaquine $(0.25 \mathrm{mg} / \mathrm{kg})$ does not cause clinically significant haemolysis in G6PD deficient subjects. PloS ONE 11, e0151898 (2016).

31. Elderfield, R. C., Mertel, H. E., Mitch, R. T., Wempen, I. M. \& Werble, E. Synthesis of primaquine and certain of its analogs. J. Am. Chem. Soc. 77, 4816-4819 (1955).

32. Allahyari, R., Strother, A., Fraser, I. M. \& Verbiscar, A. J. Synthesis of certain hydroxy analogs of the antimalarial drug primaquine and their in vitro methemoglobin-producing and glutathione-depleting activity in human erythrocytes. J. Med. Chem. 27, 407-410 (1984).

33. Walliker, D. et al. Genetic analysis of the human malaria parasite Plasmodium falciparum. Science 236, 1661 (1987).

34. D'Alessandro, S. et al. A chemical susceptibility profile of the Plasmodium falciparum transmission stages by complementary cell-based gametocyte assays. J. Antimicrob. Chemother. 71, 1148-1158 (2016).

35. Trager, W. \& Jensen, J. B. Human malaria parasites in continuous culture. Science 193, https://doi.org/10.1126/science.781840 (1976).

36. March, S. et al. Micropatterned coculture of primary human hepatocytes and supportive cells for the study of hepatotropic pathogens. Nat. Protoc. 10, 2027 (2015).

37. Tsukamoto, M., Tampo, Y. \& Yonaha, M. Lucigenin reduction by NADPHcytochrome P450 reductase and the effect of phospholipids and albumin on chemiluminescence. Biochem. Mol. Biol. Int. 45, 115-123 (1998).

38. Döhr, O., Paine, M. J. I., Friedberg, T., Roberts, G. C. K. \& Wolf, C. R. Engineering of a functional human NADH-dependent cytochrome P450 system. Proc. Natl Acad. Sci. USA 98, 81 (2001).

\section{Acknowledgements}

We thank the staff and patients of Ward 7Y and the Gastroenterology Unit, Royal Liverpool Hospital, for their generous donation of blood. We thank Mrs Jill Davies and Mrs Alison Ardrey for preparing mice for bone marrow experiments; Dr Sitthivut Charoensutthivarakal and Dr Weiqian David Hong for useful discussion on redox chemistry and advice on compound handling; Dr Eva Caamano and Dr Ghaith Aljayyoussi for help with statistical analyses. G.A.B., S.A.W., P.O.N., M.J.I.P. and D.A.B. wish to acknowledge support from the UK Medical Research Council (MC_PC_16052, MC_PC_14111 and MR/L000644/1). D.A.B. is grateful to the Wellcome Trust for support $(106240 / \mathrm{Z} / 14 / \mathrm{Z})$.

\section{Author contributions}

G.C. designed and performed experiments, analysed data and wrote the paper with contributions from all authors. P.J., R.S.P., A.S., S.M. and A.B.M. designed and performed experiments, and analysed data. M.H.L.W. and S.L. synthesised primaquine metabolites M.J.I.P. produced recombinant human CPR and gave conceptual advice on enzyme biochemistry. P.A. and G.C. produced the transgenic parasite strain used in this study. 
D.A.B., S.B., P.M.O., S.A.W. and G.A.B. provided guidance and gave conceptual advice. G.A.B conceived the study.

\section{Additional information}

Supplementary Information accompanies this paper at https://doi.org/10.1038/s41467019-11239-0.

Competing interests: S.N.B. is a co-founder of Ascendance, which commercially manufactures and distributes micropatterned co-cultures. All other authors declare no competing interests.

Reprints and permission information is available online at http://npg.nature.com/ reprintsandpermissions/

Peer review information: Nature Communications thanks Katja Becker and Larry Walker for their contribution to the peer review of this work. Peer reviewer reports are available.
Publisher's note: Springer Nature remains neutral with regard to jurisdictional claims in published maps and institutional affiliations.

(c) (i) Open Access This article is licensed under a Creative Commons Attribution 4.0 International License, which permits use, sharing, adaptation, distribution and reproduction in any medium or format, as long as you give appropriate credit to the original author(s) and the source, provide a link to the Creative Commons license, and indicate if changes were made. The images or other third party material in this article are included in the article's Creative Commons license, unless indicated otherwise in a credit line to the material. If material is not included in the article's Creative Commons license and your intended use is not permitted by statutory regulation or exceeds the permitted use, you will need to obtain permission directly from the copyright holder. To view a copy of this license, visit http://creativecommons.org/ licenses/by/4.0/.

(C) The Author(s) 2019 